\title{
IMPACT OF BROOM TWIG MINER ON BROOM GROWTH AND FLORIFORY IN CANTERBURY, NEW ZEALAND
}

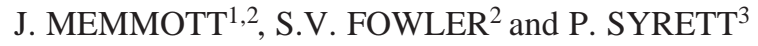 \\ ${ }^{1}$ Leverhulme Unit, NERC Centre for Population Biology, \\ Imperial College at Silwood Park, Ascot, Berks, SL5 7PY, UK \\ ${ }^{2}$ International Institute for Biological Control, CAB International, \\ Silwood Park, Ascot, Berkshire, SL5 7TA, UK \\ ${ }^{3}$ Manaaki Whenua-Landcare Research, PO Box 69, Lincoln, New Zealand
}

\begin{abstract}
The broom twigminer (Leucoptera spartifoliella) is widely distributed in New Zealand and was believed to be damaging broom plants (Cytisus scoparius) in some regions. A simple exclusion experiment was designed to investigate the impact of the broom twigminer on broom growth and floriflory. The twig miner was chemically excluded from 15 broom bushes, each bush being paired with an adjacent untreated bush. Significant differences in broom growth were observed after three months: the bushes without the twig miner increased in height by $39 \%$, while bushes with the twig miner increased by $11 \%$. No significant effects in broom growth were observed six or eleven months after the twig miner was excluded. After eleven months there was a trend towards greater florifory in the bushes without the twig miner, but the difference was not statistically significant.
\end{abstract}

Keywords: impact assessment, broom, broom twig miner, plant growth, florifory

\section{INTRODUCTION}

The broom twig miner was first recorded in New Zealand in 1950 as an accidental introduction of European origin which probably gained entry on imported ornamental broom plants (Syrett 1990). The species is now widely distributed in New Zealand (Syrett and Harman 1995), feeding solely on broom, an exotic weed species. Had the species not already been present, it would have been a primary candidate for introduction under the current programme for the biological control of broom (Syrett 1990).

Adult twig miners occur in the field from late spring to autumn (December to March); the eggs are laid on the surface of green stems and the larvae mine the chlorenchymatous tissue. The following spring, the larvae leave the stem mines to pupate elsewhere on the broom plant, usually on the underside of the stems and emerge as adults about a month later (Syrett and Harman 1995).

Given that the species is already present, the object of the work described here was to assess the impact of L. spartifoliella on broom growth and florifory using an insecticide exclusion experiment. Methods for measuring herbivore impact are essential for the effective assessment of biological control programmes.

\section{Field site}

\section{METHODS}

The field site was located 10km WSW of Hanmer Springs, North Canterbury, New Zealand (long $172^{\circ} 42^{\prime} \mathrm{E}$, lat $42^{\circ} 34.5^{\prime} \mathrm{S}$.). The study area consisted of a $50 \mathrm{~m} \mathrm{x} 60 \mathrm{~m}$ plot on a flat shingle bank in a braided river bed, a habitat in which broom is commonly found in New Zealand and an area in which high infestation levels of the twig miner had been observed.

\section{Experiment}


Fifteen pairs of bushes were chosen in the plot, each pair being matched in size (all bushes were less than $0.8 \mathrm{~m}$ in height) and form. All the bushes were approximately two years old and each were within $3 \mathrm{~m}$ of each other. The twig miner was excluded from one randomly chosen bush of each pair by killing its eggs with azinphos methyl (Gusathion as a wettable powder $350 \mathrm{~g} / \mathrm{kg}$ ), an insecticide applied as an early morning spray. While being sprayed, a large plastic tube was placed over each bush to prevent spray drifting to adjacent plants. Egg-laying by the twig miner peaks in January/February (Syrett pers. obs.) and a single application of azinphos methyl at the end of January was sufficient to prevent eggs from hatching.

Bush height was measured before the chemical treatment and 3, 6 and 11 months thereafter. Infestation levels of the twig miner were recorded 3 months after spraying, for five randomly chosen twigs on each bush (mean length of each twig: $22.68 \mathrm{~cm}$ ). The mines of individual twig miners were difficult to differentiate at high infestations and in most cases it was impossible to count individual mines. Therefore, rather than attempting to make an exact count of the number of larvae per individual twig, the number of $5 \mathrm{~cm}$ sections of twig which contained mines was recorded. The $5 \mathrm{~cm}$ sections were summed and divided by twig length to give a percentage infestation of the twig miner per twig.

The following spring, 11 months after the spray application, the bushes flowered and the degree of florifory was compared between each pair of bushes. The pairs were visually estimated as being equally floriforous, the sprayed bush being more floriforous, or the control bush being more floriforous.

\section{Levels of broom twig miner infestation}

\section{RESULTS}

Three of the fifteen pairs of bushes were grazed by hares and were excluded from the analysis. Ten percent $\pm 9.0 \%$ of the sixty twigs on the sprayed bushes and $98 \% \pm 3.3 \%$ of the sixty twigs on the control bushes contained twig miners. The percentage twig miner infestation also differed, with the sprayed bushes having an average of $4 \% \pm 4.4 \%$ of twigs infested and the control bushes having an average of $64 \% \pm 9.8 \%$ of twigs infested. Thus, azinphos methyl provided a simple and effective means of twig miner exclusion.

\section{Broom growth rates}

In the three month interval between spraying and the census, the sprayed bushes

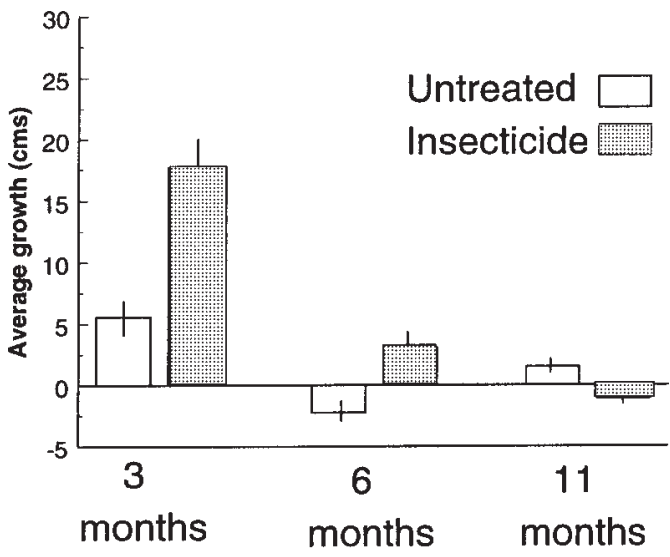

FIGURE 1: The average growth of broom bushes, naturally infested with L. spartifoliella, 0-3, 4-6 and 7-11 months after one of each pair was sprayed with insecticide. $95 \%$ confidence intervals are shown for both sprayed and control bushes. 
grew significantly more than the unsprayed bushes, (paired t-test: $\mathrm{t}=4.88, \mathrm{P}<0.0001$, Fig. 1). On average, the sprayed bushes increased in height by $39 \%$ and the unsprayed bushes by $11 \%$. Six and 11 months after the spray application, no significant differences in broom growth were observed, $(\mathrm{t}=0.25, \mathrm{P}<0.8$ and $\mathrm{t}=0.17, \mathrm{P}<0.87$ respectively, Fig. 1). However, there remained a difference in the overall growth in the bushes over the whole 11 month period $(\mathrm{t}=3.75, \mathrm{P}=0.011)$ although obviously this difference was due to the growth during the first three months of the experiment.

After three months in the untreated bushes, there was a negative relationship between bush size and the degree of twig miner infestation, $(\mathrm{r}=0.84, \mathrm{P}<0.05$, Fig. 2a). Thus smaller bushes were more heavily infested with twig miners. One of the data points is an outlier $\left(\mathrm{r}_{\mathrm{i}}{ }^{\prime}=2.84\right)$ having a much lower twig miner infestation than would be expected on the basis of its size. There was no obvious explanation for the difference, this particular plant was towards the centre of the plot and appeared similar to the other plants. There was no relationship between bush size and the degree of twig miner infestation for the sprayed bushes ( $r=0.35, \mathrm{P}>0.05$, Fig. $2 b)$.

To investigate whether the higher infestation levels of the smaller bushes led to a greater curtailment of their growth rates, the effect of bush size on growth rate was
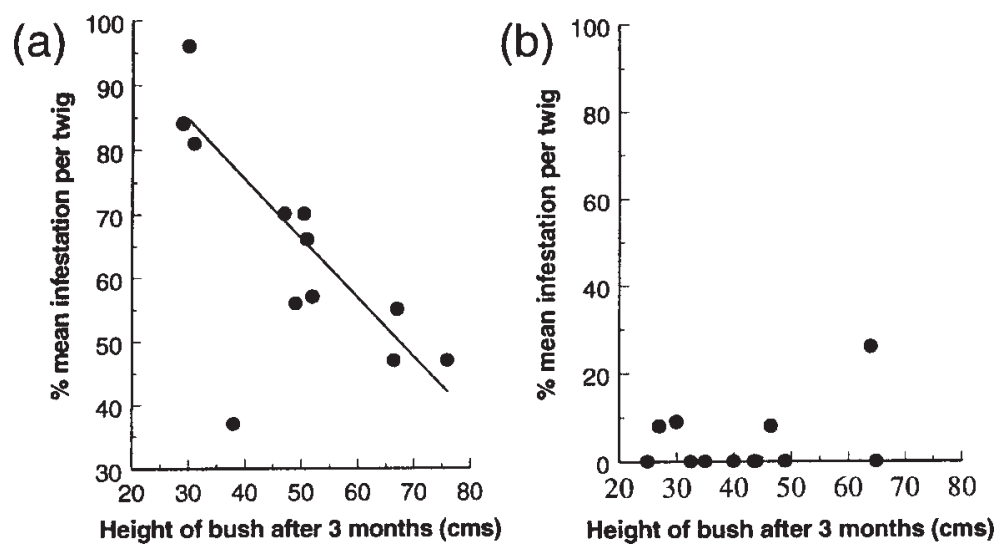

FIGURE 2: The mean twig miner infestation per bush vs the height of the bush for (a) controls and (b) sprayed bushes. Infestation levels were measured three months after spraying and were significantly related to bush height three months after spraying in the unsprayed controls.

assessed. There was a significant relationship between size and growth rate for the control bushes, $(r=0.58, P<0.05$, Fig. $3 a)$ but no relationship between size and growth rates for the sprayed bushes, $(r=0.009, P>0.05$, Fig. 3b). This indicates that the smaller bushes were growing less than the larger bushes, and that this effect was caused by their higher infestation levels of the twig miner.

\section{Florifory}

In 11 of the 12 pairs, at least one of the bushes flowered. The pattern of florifory was as follows: one pair of plant were equally floriforous, one pair of plants had a more floriforous untreated bush, eight pairs of plants had more floriforous sprayed bushes and in one pair of bushes neither plants flowered. A sign test was used to test whether there was a difference in the degree of floriflory between the two classes. Thus, the plant that was more floriforous in a pair was given a plus symbol and the less floriforous plant a minus symbol. The sign test simply tests the hypothesis that the 12 plus and minus signs are sampled from a population in which the two kinds of signs are present in equal 

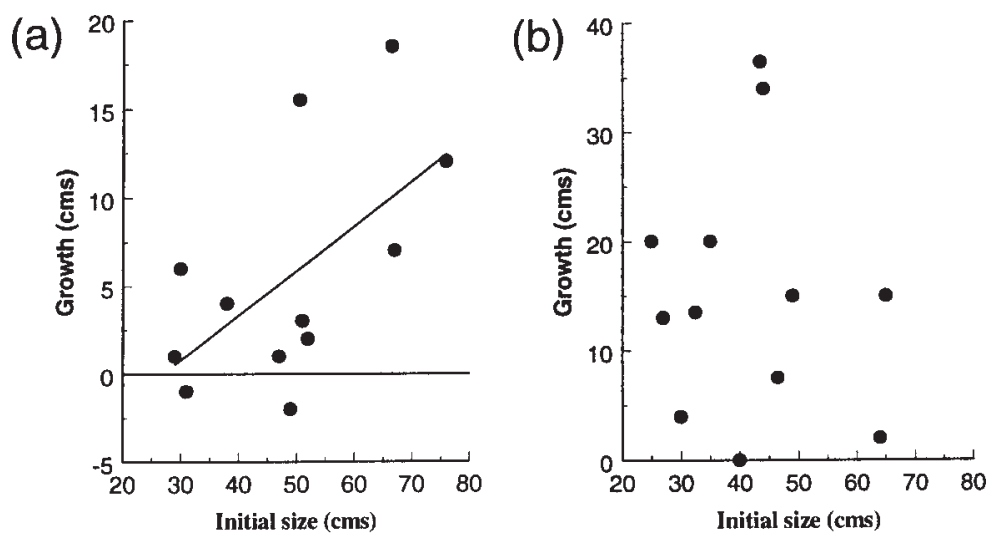

FIGURE 3: The growth of bushes and their height at the beginning of the experiment for (a) unsprayed controls and (b) sprayed bushes. Growth was measured three months after spraying and it was significantly related to initial height in the unsprayed controls.

proportions. There was no significant difference between the sprayed and unsprayed bushes, $\mathrm{S}=3, \mathrm{P}>0.05$, although the results indicate a trend towards reduced flowering in the twig miner infested bushes.

\section{DISCUSSION}

Because azinphos methyl is a broad spectrum insecticide, it was impossible to attribute the differences in broom growth solely to the twig miner. However, the herbivores found on broom in New Zealand would have peaked in abundance two months before the insecticide was applied (Syrett 1993). No other insects were observed feeding on the broom during the setting up or the sampling of the experiment, despite detailed observation while quantifying twig miner damage on 120 twigs. Thus, most of the difference in broom growth probably could be attributed to the twig miner. Little broom growth occurred in the winter or the first half of spring, thus the main period of broom growth in New Zealand was during the second half of spring, the period when the twig miner was active. The observed shrinkage of some bushes, was probably explained by the observation that dead twig tips (killed by the twig miner) break off over the winter period.

Why smaller bushes were, in general, more heavily infested is not clear. They could be smaller because they have been more heavily infested in previous years or the twig miner may prefer smaller bushes. The fact that one of the bushes was attacked to a much lesser extent than the others suggests that there may be some variation in host plant susceptability. The level of the twig miner infestation was similar to that described in two other sites in New Zealand (Syrett1993) and considerably greater than the levels normally reached in England (Agwu 1967) and mainland Europe (Fowler pers. obs.).

Waloff and Richards (1977) sprayed herbivores off broom at Silwood Park, England and demonstrated increased growth, longevity and fecundity of the plant. The broom fauna in New Zealand is meagre in comparison to Europe (Syrett 1993) but there was still a significant effect on broom growth when just a single member of this fauna was excluded.

Successful biological control consists of two stages: a suppression in plant abundance and the maintenance of low abundance following suppression. The factors which cause suppression may not be the same as those which maintain numbers at a low level (Roland 
1994). We do not know whether the twig miner has successfully suppressed broom populations as there are no data on broom growth and vigour before its arrival in New Zealand. However, from the results presented here, we can claim that at some sites, the twig miner is causing a reduction in broom growth 50 years after its introduction to New Zealand.

\section{ACKNOWLEDGEMENTS}

We would like to thank Helen Harman for helping with the fieldwork and John Clapham for introducing us to the fieldsite. We are grateful to The British Council Higher Education Links Scheme for providing travel funds for S.V. Fowler and to both the Leverhulme Trust and the Royal Society for funding J. Memmott.

\section{REFERENCES}

Agwu, S.I., 1967. The biology and population dynamics of Leucoptera spartifoliella (Hb) on broom (Sarothamnus scoparius). Univ. London PhD Thesis.

Roland, J., 1994. After the decline: what maintains low winter moth after successful biological control? J. Anim. Ecol. 63: 392-398.

Syrett, P., 1990. The impact of the self introduced twigmining moth Leucoptera spartifoliella on broom (Cytisus scoparius) in New Zealand. Pp. 537-540 In: Proceedings of the 7th International Symposium on Insect-Plant Relationships 1989, Budapest, Hungary, Akadémiae Kiadó, Budapest.

Syrett, P., 1993. The insect fauna of broom, Cytisus scoparius, in New Zealand. N.Z. Entomologist. 16: 75-83.

Syrett, P. and Harman, H.M., 1995. Leucoptera spartifoliella (Hubner) as a biological control agent for broom in New Zealand. Plant Prot. Quart. 10: 75-78.

Waloff, N. and Richards, O.W., 1977. The effect of insect fauna on growth, mortality and natality of broom, Sarothamnus scoparius. J. Appl. Ecol. 14: 787-98. 